\title{
MODEL PRODUKSI DAUN PADA HUTAN TANAMAN \\ KAYU PUTIH (Melaleuca cajuputi Subsp. cajupti POWELL) SISTEM PEMANENAN PANGKAS TUNAS
}

\author{
(Leaves Production Model of Kayu Putih (Melaleuca cajuputi Subsp. cajupti Powell) \\ Plantation on Sprout Cutting System)
}

\author{
Pudja Mardi utomo ${ }^{1)}$, Endang Suhendang ${ }^{2)}$, Wasrin Syafii ${ }^{2}$, \\ dan/and Bintang C.H. Simangunsong ${ }^{2}$ \\ ${ }^{1)}$ Balai Penelitian Kehutanan Manokwari \\ J1. Inamberi-Pasir Putih PO Box 159 manaokwari Papua Barat \\ Telp. (0986) 213437-213440, Fax (0986) 213441 \\ 2) Fakultas Kehutanan, Institut Pertanian Bogor \\ Kampus Darmaga, Jl. Raya Darmaga Bogor
}

Naskah masuk : 25 Juni 2012; Naskah diterima : 29 November 2012

\begin{abstract}
Cajuput oil is one of important non-timber forest product in Indonesia, which is resulted from processing of kayu putih (Melaleuca cajuputi Subsp. cajuputi Powell) leaves. Perum Perhutani is now managing about 24,000 hectars of kayu putih plantation in Java and 10 units of leaves processing mills with installed capacity of 53,760 tonnes per year. However, these mill were not optimally operation due to low leaves kayu putih production. The objective of this study were: (1) to develop kayu putih leaves production model, for one leaves harvesting rotation, and (2) to develop kayu putih leaves production model for one biological rotation, to determine a silviculture rotation age of kayu putih stand. Subject to field condition, number of tree, stand density, and biomass by part of tree from 36 temporary sample plot (TSP) of Age Class II at BKPH Sukun were then measured to develop kayu putih leaves production model and from 24 TSP of all Age Class (Age Class I - VIII) at BKPH Sukun were measured to determine a biological rotation age. The result show that Morgan-Mercer-Flodin (MMF) equation was the best model representing kayu putih leaves production model, with option sprout age of 7 months. Polynomial equation was a model inrepresenting kayu putih leaves production model. A biological rotation age was estimated around 25 years (with Age Class V).
\end{abstract}

Keywords: Leaves production model,cajuput oil, rotation, kayu putih

\begin{abstract}
ABSTRAK
Kayu putih merupakan salah satu hasil hutan non kayu yang penting di Indonesia. Hutan tanaman kayu putih di Jawa cukup besar, diperkirakan Perum Perhutani mengelola sekitar 24.000 ha areal produktif jenis ini dan memiliki 10 Pabrik Pengolahan Minyak Kayu Putih (PMKP). Namun Pengelolaannya belum optimal karena sampai saat ini produksi daun kayu putih masih jauh dari kapasitas terpasang pabrik, yaitu sebesar 53.760 ton daun kayu putih per tahun. Tujuan penelitian adalah: (1) mengetahui model produksi daun tanaman kayu putih dalam satu periode pemangkasan dan (2) mengetahui model produktivitas daun tanaman kayu putih dalam satu daur biologis. Hasil model yang diperoleh digunakan untuk menentukan saat daun dipanen dan saat tanaman kayu putih diganti dengan tanaman baru. Metode pengambilan data dilakukan dengan survey, pengamatan langsung di lapangan dengan pengukuran plot-plot ukur sementara (PUS). Plot ukur untuk pembuatan model dalam satu daur panen dibuat sebanyak 36 PUS dan 24 PUS untuk pembuatan model dalam satu daur biologis. Model produksi daun kayu putih terbaik dalam satu daur panen adalah Morgan-Mercer-Flodin model (MMF) dan pemangkasan optimum adalah pada umur tunas 7 bulan, dimana kurva laju pertumbuhan rata-rata bulanan maksimum berpotongan dengan kurva pertumbuhan bulan berjalan. Model produktivitas dalam satu daur silvikulktuyr adalah model polinomial. Daur biologis atau saat tanaman diganti dengan tanaman baru diperkirakan pada umur 25 tahun (kelas umur V), dimana produk-tivitas setelah umur ini menurun.
\end{abstract}

Kata kunci : Model produksi daun, minyak kayu putih, kayu putih 


\section{PENDAHULUAN}

\section{A. Latar Belakang}

Tanaman kayu putih (Melaleuca cajuputi subsp. cajuputi) atau dalam literatur lama sering juga disebut Melaleuca leucadendron merupakan salah satu jenis pohon dari famili Myrtaceae merupakan tanaman asli Indonesia yang cukup penting bagi industri minyak atsiri. Di Indonesia umumnya tanaman kayu putih berwujud sebagai hutan alam dan hutan tanaman. Hutan alam terdapat di Maluku (pulau Buru, Seram, Nusa Laut dan Ambon), Sulawesi Tenggara, Bali, Nusa Tenggara Timur, dan Papua, sedangkan yang merupakan hutan tanaman ada di Jawa Timur (Ponorogo, Kediri, Madiun), Jawa Tengah (Solo dan Gundih), Daerah Istimewa Yogyakarta dan Jawa Barat (Banten, Bogor, Sukabumi, Indramayu, Majalengka)(Gunn, et al., 1996; Mulyadi, 2005; Perum Perhutani, 2005).

Potensi tanaman kayu putih di Jawa cukup besar, diperkirakan Perum Perhutani mengelola sekitar 24.000 ha jenis ini dan memiliki 10 pabrik pengolahan minyak kayu putih (PMKP). Pabrik yang dimiliki Perum Perhutani tersebar di Pulau Jawa, yaitu, 5 unit di Jawa Timur, 4 unit di Jawa Barat dan satu unit di Jawa Tengah. Kapasitas terpasang pabrik total kesepuluh PMKP tersebut sebesar 53.760 ton daun kayu putih per tahun. Tanaman jenis ini di Pulau Jawa sudah dibudidayakan secara komersial dengan produksi minyak mencapai 300 ton/tahun (Rimbawanto, et al.2009).

Perum Perhutani (2010) menyebutkan bahwa Indonesia merupakan salah satu importir minyak kayu putih. Berdasarkan data statistik, kebutuhan domestik minyak kayu putih sebesar 1.500 ton per tahun tetapi kemampuan produksi minyak Indonesia hanya 500 ton per tahun. Padahal seperti telah disebutkan di atas potensi hutan tanaman kayu putih di Jawa cukup besar yang sampai dengan saat ini belum mampu memenuhi kebutuhan daun kayu putih sesuai dengan kapasitas terpasang pabrik.

Dilihat dari segi kualitas tegakan dan rendemen minyak juga masih rendah. Hal ini ditunjukan dengan besarnya derajat kesempurnaan tegakan (Dkn) antara 0,21 sampai dengan 0,81. Sebagai gambaran, hasil kajian Utomo (2001) hutan tanaman kayu putih di BKPH Sukun hanya memiliki Dkn rata-rata 0,68 dengan produksi daun kayu putih 4.875 ton/tahun, dengan rendemen minyak dari tegakan kurang dari 1,0\%.
Sedangkan pada periode 2006 - 2010 rata-rata produksi mencapai 6.318 ton daun kayu per/ tahun dengan rendemen minyak 0,8 (Perum Perhutani, 2011).

Hal tersebut mengindikasikan bahwa pengelolaan hutan tanaman kayu putih di Jawa belum optimum. Oleh karena itu perlu dicari jalan keluar agar produktivitas daun kayu putih meningkat. Sambil menunggu hasil penelitian pembuatan tanaman melalui rekayasa genetika dan manipulasi tempat tumbuh, perlu disusun rencana pengaturan hasil yang optimum dari tegakan tanaman kayu putih ada saat ini. Selama ini praktek pengelolaan hutan tanaman kayu putih di Pulau Jawa dilakukan dengan sistem pemangkasan tunas dan belum memperhatikan model pertumbuhan dan hasil tunas, sehingga produksi daun kayu putih tidak maksimal.

Salah satu informasi penting dalam pengaturan hasil adalah model pertumbuhan dan hasil. Namun demikian, model pertumbuhan dan hasil tanaman kayu putih dengan sistem pangkas tunas belum diketahui, padahal ini sangat diperlukan. Informasi pertumbuhan pada setiap periode tumbuh dan berkembang tanaman kayu putih dapat digunakan untuk mengetahui saat kapan produksi daun kayu putih optimal untuk dipungut. Selain itu, informasi ini juga dapat dipakai untuk mengetahui kapan umur tunas mempunyai kualitas dan rendemen yang tinggi.

Berdasarkan informasi dari model pertumbuhan dan hasil dapat dibuat skenario pemanenan melalui penjadwalan pemangkasan pada umur tunas berapa daun kayu putih mempunyai produktivitas dan kualitas minyak tertinggi atau kombinasi antara produktivitas daun dan kualitas minyak tertinggi dalam satu periode panen. Untuk mencapai hasil yang diharapkan maka perlu dilakukan kajian ilmiah tentang model pertumbuhan dan hasil tunas daun kayu putih yang dapat digunakan sebagai alat dalam pengaturan hasil sebagai dasar menyusun model pengelolaan hutan yang mampu mengatasi masalah produksi daun kayu putih.

Salah satu cara untuk menentukan preskripsi pemangkasan (intensitas pangkasan dan lama rotasi) yang optimum adalah dengan memaksimumkan daun kayu putih atau selanjutnya disingkat DKP (merupakan campuran antara ranting dan cabang yang berdiameter $<0,5 \mathrm{~cm}$ ) melalui model pertumbuhan tunas optimum. Dengan mengetahui model ini akan diperoleh kurva pertumbuhan total tunas maksimum, riap ratarata bulanan tunas dan riap bulan berjalan. Selain 
itu juga akan diperoleh informasi dimana DKP mempunyai kualitas dan rendemen minyak yang tinggi.

Penelitian tentang model pertumbuhan dan hasil beberapa jenis pada tegakan hutan tanaman sudah banyak dilakukan. Sebaliknya, hingga saat ini belum ada studi di Indonesia yang menggunakan model pertumbuhan dan hasil selanjutnya disebut model produksi daun kayu sistem pemanenan pangkas tunas, padahal informasi seperti itu sangat dibutuhkan oleh pengelola hutan khususnya kelas perusahaan kayu putih.

Permasalahan yang ada dalam penyusunan rencana pengelolaan hutan khususnya di hutan kayu putih adalah belum ditemukan metode yang tepat terutama kaitannya dengan pengaturan hasil. Salah satu hal penting dalam menyusun pengaturan hasil adalah informasi model produksi daun yang dapat digunakan untuk bahan pertimbangan dalam meningkatkan produktivitas daun kayu putih. Sehubungan dengan informasi tentang pertumbuhan dan hasil tanaman kayu putih belum tersedia, maka perlu dilakukan pembuatan model produksi daun kayu putih.

Akhirnya untuk mengantisipasi permasalahan tersebut perlu dibuat model produksi daun kayu putih yang handal. Dengan strategi tersebut diharapkan diperoleh produktivitas daun kayu putih dan kualitas minyak kayu putih yang tinggi.

\section{B. Tujuan}

Tujuan umum adalah mendapatkan model produksi daun kayu putih sistem pemanenan pangkas tunas pada hutan tanaman kayu putih. Sedangkan tujuan khusus adalah:

1. Mendapatkan model produksi daun tanaman kayu putih dalam satu periode panen atau pemangkasan.

2. Mendapatkan model pertumbuhan dan hasil tanaman kayu putih dalam satu daur silvikultur.

\section{BAHAN DAN METODE}

\section{A. Tempat dan Waktu}

Penelitian dilakukan di wilayah Bagian Kesatuan Hutan Sukun (BKPH), Kesatuan Pemangkuan Hutan Madiun, Perum Perhutani Unit II Jawa Timur. BKPH Sukun termasuk Bagian Hutan Ponorogo Timur, Kesatuan Pemangkuan Hutan Madiun merupakan Kelas Perusahaan Kayu Putih terletak disebelah Barat Daya Gunung Wilis. Secara administratif termasuk wilayah Kecamatan Pulung, Siman, Mlarak dan Jenangan, Kabupaten Ponorogo, Provinsi Jawa Timur. Peta lokasi penelitian dapat dilihat pada Gambar 1.

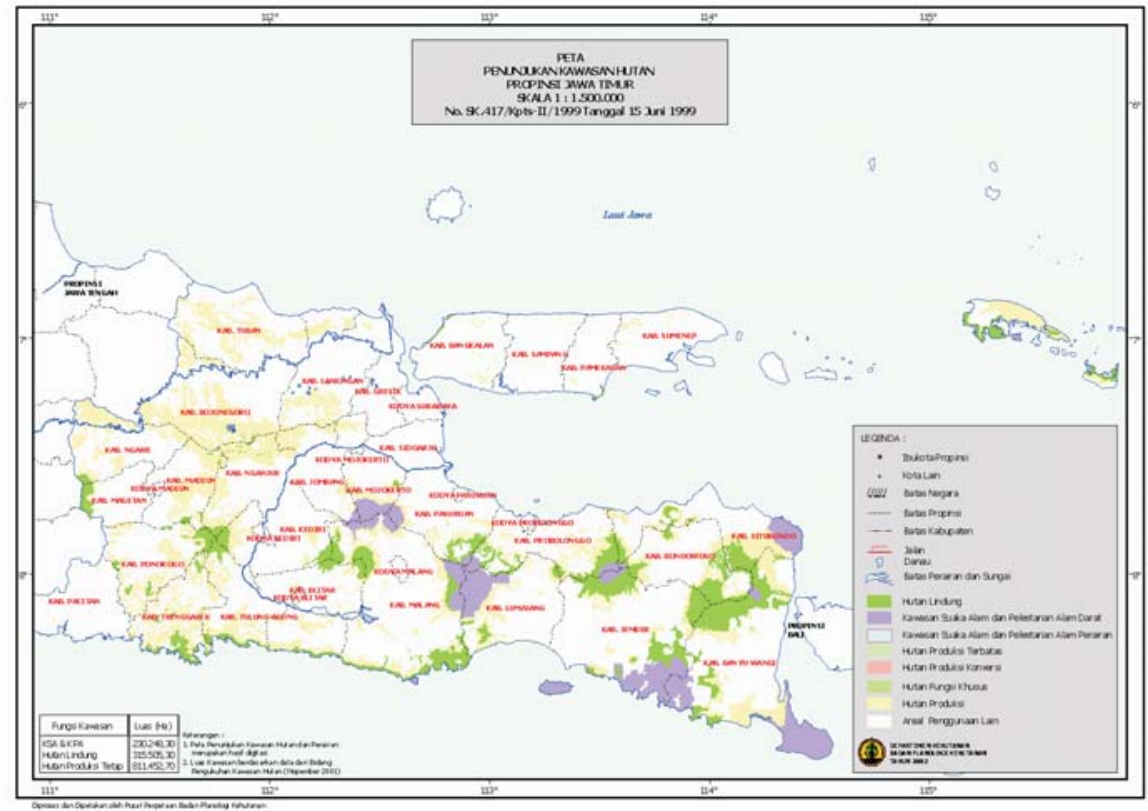

Gambar(Figure) 1. Peta lokasi penelitian di Ponorogo, Jawa Timur (Map of research location at Ponorogo, East Java) 
BKPH Sukun ini dipilih sebagai lokasi penelitian karena merupakan tempat yang cukup ideal untuk menyusun model produksi daun dalam rangka menyusun model pengelolaan hutan tanaman kayu putih yang optimum. Dasar Pertimbangannya antara lain mempunyai luas areal hutan produksi \pm 3.450 ha, tegakan kayu putih mempunyai kelas umur yang lengkap (KU I sampai dengan KU IX), produktivitas daun kayu putih di BKPH Sukun belum maksimal, kapasitas terpasang pabrik belum pernah terpenuhi dan di areal hutan ini memungkinkan pelaksanaan kegiatan tumpangsari sepanjang tahun.

\section{B. Bahan dan Alat}

Bahan penelitian untuk menyusun model produksi daun adalah tegakan tanaman kayu putih dengan umur tunas 1 bulan sampai dengan umur 12 bulan pada kelompok umur II. Tegakan tanaman kayu putih Kelompok Umur (KU) I sampai dengan Kelompok Umur VIII yang mempunyai umur tunas 12 bulan.

Alat yang digunakan dalam penelitian ini antara lain : pita ukur/meteran logam 5 meter, galah berskala, timbangan, tally sheet, kantung plastik, alat tulis, kamera, seperangkat komputer dan perangkat lunaknya.

\section{Batasan dan Istilah}

\section{Populasi}

Populasi dalam penelitian ini adalah himpunan dari tegakan-tegakan tanaman kayu putih (M. cajuputi) yang memiliki umur tunas satu bulan sampai dengan dua belas bulan dan tegakan tanaman kayu putih seluruh kelompok umur yang ada pada Kelas Perusahaan Kayu Putih BKPH Sukun, KPH Madiun.

\section{Plot ukur}

Vanclay (1994) menyatakan bahwa data riap tegakan dapat diperoleh dengan melakukan inventarisasi, yaitu inventarisasi secara statis (static inventory) maupun secara dinamis (dynamic inventory). Inventarisasi statis ditujukan untuk mengetahui potensi tegakan pada suatu waktu tertentu dilakukan dengan menggunakan plot ukur sementara - PUS (temporary sample plot $T S P$ ), sedangkan inventarisasi dinamis yang ditujukan untuk mengumpulkan informasi pertumbuhan tegakan dari waktu ke waktu dilakukan dengan pembuatan plot ukur permanen - PUP (permanent sample plot - PSP). Berhubung pada lokasi penelitian tidak tersedia plot permanen, maka dalam penelitian ini plot ukur yang digunakan adalah plot ukur sementara (PUS).

\section{Satuan contoh}

Satuan contoh yang digunakan adalah Plot Ukur Sementara (PUS) berbentuk persegi atau bujur sangkar. Dari hasil penelitian yang dilakukan sebelumnya bentuk PUS yang digunakan adalah bujur sangkar dengan ukuran $25 \mathrm{~m}$ x $25 \mathrm{~m}$.

\section{Dimensi pohon yang diukur}

Dimensi tegakan utama yang diselidiki dalam penelitian ini adalah volume biomassa $(\mathrm{kg})$ tunas tanaman kayu putih, berupa berat total tunas, berat dahan atau ranting dan berat daun kayu putih yang dipakai sebagai bahan baku industri, sedangkan beberapa informasi tegakan lain yang dicatat adalah umur tanaman atau kelompok umur (tahun) dan umur tunas (bulan). Pohon contoh yang akan diambil adalah tanaman kayu putih pada tegakan yang berkondisi baik dan mempunyai pertumbuhan normal setiap umur tunas. Adapun cara pengukurannya adalah sebagai berikut: (1) produksi daun per pohon kayu putih adalah besarnya massa daun yang dapat dipungut dari satu pohon kayu putih yang diukur dengan timbangan digital yang berkapasitas $40 \mathrm{~kg}$, (2) umur pangkas atau umur tunas dihitung mulai pemangkasan sebelumnya sampai saat pengukuran, yang dinyatakan dalam bulan, (3) umur tanaman diperoleh dari Buku RPKH Pengusahaan Kayu Putih KPH Madiun Perum Perhutani Unit II Jawa Timur dan konfirmasi langsung dengan petugas lapangan (KRPH dan Mandor).

\section{Jenis dan Cara Pengumpulan Data}

\section{Jenis data}

Data yang dikumpulkan meliputi data primer dan data sekunder. Data primer adalah data yang diperoleh secara langsung di lapangan melalui pengukuran plot-plot ukur yang dibuat pada areal kerja BKPH Sukun, KPH Madiun, Perum Perhutani Unit II Jawa Timur. Data sekunder berupa keadaan umum daerah penelitian dan data pendukung lainnya dari kantor lingkup Perum Perhutani dan Pemerintah Daerah. Jenis data diuraikan sebagai berikut:

\section{a. Data primer}

Data primer dalam penelitian ini diperoleh dari hasil pengukuran pohon-pohon dalam plotplot ukur sementara (PUS) pada Petak kerja BKPH Sukun dan Penyulingan daun dan uji minyak kayu putih di laboratorium Balitro Bogor.

1) Data pengukuran produksi daun kayu putih satu kali pemanenan tunas

Data diperoleh dari hasil pengukuran pohonpohon dalam plot-plot ukur sementara (PUS) yang 
mempunyai umur tunas 1 bulan sampai dengan 12 bulan dan diletakkan tersebar pada Petak 5a dan Petak 6 BKPH Sukun. Pada masing-masing umur tunas dibuat 3 PUS berbentuk bujur sangkar dengan ukuran $25 \mathrm{~m}$ x $25 \mathrm{~m}$. Seluruh pohon dalam PUS diukur dan dicatat berat biomassanya. Petak 5a dan 6 merupakan petak tegakan tanaman kayu putih KU II tahun tanam 2006 dengan luas masing-masing 83,7 ha dan 44,0 ha.

2) Data pengukuran produksi daun kayu putih satu daur biologis

Data diperoleh dari hasil pengukuran pohonpohon dalam plot-plot ukur sementara yang mempunyai umur tunas 12 bulan dan diletakkan tersebar pada petak-petak kerja BKPH Sukun, yaitu: Petak 34f, Petak 5a, Petak 3a, Petak 9a, Petak 6a, Petak 19b, Petak 19a, dan Petak 17b. Petak-petak tersebut terdiri dari KU I sampai dengan KU VIII, dimana selang KU adalah 5 tahun. Masing-masing KU dibuat 3 PUS berbentuk bujur sangkar dengan ukuran $25 \mathrm{~m}$ x $25 \mathrm{~m}$. Seluruh pohon dalam PUS diukur dan dicatat berat biomassanya.

3) Data Kadar minyak, kualitas dan beberapa sifat minyak kayu putih

\section{b. Data sekunder}

Data untuk melengkapi data primer, yang diperoleh dari instansi pemerintah maupun swasta yang ada kaitannya dengan penelitian; seperti Perum Perhutani,

Pemerintah Daerah dan perindustrian, data tersebut antara lain:

1) Data yang dikumpulkan dari kantor Perum Perhutani, meliputi:

a) Risalah hutan kayu putih BKPH Sukun,

b) Pengelolaan hutan kayu putih BKPH Sukun,

c) Peta BKPH Sukun dan peta yang terkait lainnya,

d) Produksi daun dan minyak kayu putih ,

e) Pengelolaan tumpangsari di lahan hutan kayu putih dan informasi lainnya.

2) Data yang dikumpulkan dari Pemerintah Daerah, meliputi:

a) Keadaan umum daerah yang termasuk didalamnya adalah letak dan luas wilayah, topografi, iklim dan tanah,

b) Kependudukan yang meliputi: jumlah penduduk menurut umur,

c) Tata guna dan pemikan lahan,

d) Produksi dan Produktivitas lahan,

e) Jumlah dan pemilikan ternak,

f) Keadaan bangunan rumah masyarakat dan data terkait lainnya.
3) Data Fisik Lingkungan, yaitu:

a) Kesuburan tanah,

b) Curah hujan 10 tahun terakhir.

4) Data dari industri, yaitu:

a) Kapasitas pabrik minyak kayu putih,

b) Produksi minyak kayu putih.

\section{Cara pengumpulan data}

Cara pengumpulan data dalam penelitian ini dilakukan secara langsung melalui pengukuran plot-plot ukur di hutan tanaman areal kerja BKPH Sukun untuk memperoleh data primer. Data sekunder diperoleh melalui pengutipan laporanlaporan yang ada di lingkup Perum Perhutani dan dari instansi terkait lainnya. Bagaimana cara pengumpulan data masing-masing tujuan diuraikan di bawah ini. Jenis data, sumber atau cara memperoleh data, dan metodenya secara ringkas dapat dilihat pada Tabel 1.

\section{a. Model produksi daun pada satu daur pemanenan tunas}

Pengambilan data pohon contoh untuk pembuatan model produksi daun adalah hasil pengukuran PUS pada petak tanaman kayu putih kelompok umur (KU) II dan mempunyai umur tunas 1 bulan sampai dengan 12 bulan. Tegakan tanaman pada KU II dipilih sebagai lokasi penempatan plot-plot contoh dengan alasan antara lain kerapatan tegakan $>95 \%$ dan kondisi lahan relatif seragam. Hal ini bisa meminimalisir keragaman akibat perbedaan tempat tumbuh. PUS diletakan menyebar ke seluruh petak sesuai dengan umur tunasnya. Pada masing-masing umur tunas tegakan tanaman kayu putih dibuat 3 PUS. Pada penelitian ini umur tunas yang diamati adalah umur 1 - 12 bulan, maka banyaknya PUS untuk pembuatan model produksi daun dalam satu daur pemanenan adalah 36 buah atau setiap umur tunas diulang $3 \mathrm{x}$, Pohon yang ada dalam PUS seluruhnya diukur untuk memperoleh data yang representatif. Data yang diperoleh dari PUS berupa biomassa (Semua bagian pohon yang dipangkas) dan berat DKP (Campuran antara daun dan ranting dengan diameter $<0,5 \mathrm{~cm}$ ) semua pohon.

\section{b. Model Produksi Daun pada Satu Daur Pemanenan Tunas}

Untuk memperoleh data dalam rangka menyusun model produksi daun pada satu daur silvikultur dilakukan dengan cara yang sama seperti di atas. Namun ada perbedaan pada cara penempatan PUS-nya. Pada kasus ini PUS diletakan pada tegakan kayu putih yang mempunyai KU I - VIII. Perbedaan lainnya adalah setiap plot tidak ditempatkan pada Petak atau Anak Petak yang 
sama. Banyaknya PUS unruk membuat model produksi daun pada satu daur silvikultur adalah 24 buah

\section{Riap}

Menurut Prodan (1968), riap dibedakan ke dalam riap tahunan berjalan (Current Annual Increment, disingkat CAI), riap periodik (Periodict Increment, disingkat PI) dan riap rata-rata tahunan (Mean Annual Increment, disingkat MAI). CAI adalah riap dalam satu tahun berjalan, PI adalah riap dalam satu periode waktu tertentu, sedangkan MAI adalah riap rata-rata (per tahun) yang terjadi sampai periode waktu tertentu. Sedangkan untuk tanaman kayu putih pertumbuhan atau riap (increment) adalah pertambahan tumbuh tanaman kayu putih, berupa berat biomassa dan DKP (Daun kayu putih sebagai bahan baku industri) dalam satuan waktu tertentu. Pertumbuhan berat biomassa dapat digambarkan sebagai riap bulanan berjalan (curren monthly increment $=C M I$ ) dan riap bulanan rata-rata (mean monthly increment=MMI). Kedua bentuk riap tersebut, secara matematis dapat ditulis sebagai berikut:

a. $\mathrm{CMI}=\mathrm{V}_{\mathrm{A}}$

b. $\mathrm{MMI}=\mathrm{V}_{\mathrm{A}} / \mathrm{A}$

dimana:

$\mathrm{V}_{\mathrm{A}}=$ pertumbuhan kumulatif biomassa tegakan sampai umur A

$\mathrm{V}^{\prime}{ }_{\mathrm{A}}=$ turunan pertama kurva pertumbuhan kumulatifbiomassa tegakan

$\mathrm{A}=$ umur (bulan)

\section{E. Analisis Data}

Analisis data yang akan dilakukan adalah analisis terhadap model regresi linear dan non- linear yang diperoleh baik untuk model produksi daun pada satu daur panen maupun pada satu daur silvikultur. Analisis, jenis data, sumber data, dan metodenya secara ringkas dapat dilihat pada Tabel 1.

Dari hasil kajian beberapa literatur fungsi pertumbuhan adalah model yang berasimtot. Beberapa model yang sering digunakan dalam fenomena-fenomena biologi antara lain: fungsi Logistic, Gompertz, Von-Bartalanffy, Negative exponential, Monomolekuler, Log-logistic, Richard's, Weibull, Chapman-Richards, Morgan-MercerFlodin, Polinomial, Kuadratik dan lain-lain. Beberapa contoh model matematis pertumbuhan yang akan digunakan dapat dilihat di bawah ini. Kurva dibuat berdasarkan metode kurva panduan (guide curve) yang dianalisis berdasarkan regresi linear dan non linier.

$\mathrm{Y}=\beta_{0}+\beta_{1} \mathrm{~A}+\beta_{2} \mathrm{~A}^{2}$

Model Polinomial (Prodan, 1968)

$\mathrm{Y}=\left(\beta_{0} \mathrm{~A}^{2}\right) \exp \left(-\beta_{1} \mathrm{~A}\right)$

Model Huggershoff(Prodan, 1968)

$\mathrm{Y}=\beta_{0} /\left(1+\beta_{1} \exp \left(-\beta_{2} \mathrm{~A}\right)\right)$

Model Logistic (Nelder, 1961; Oliver, 1964)

$\mathrm{Y}=\beta_{0} \exp \left(-\beta_{1} \exp \left(-\beta_{2} A\right)\right)$

Model Gompertz, (Draper dan Smith, 1981)

$\mathrm{Y}=\beta_{0} /\left[1-\beta_{1} \exp \left(-\beta_{2} \ln \mathrm{A}\right)\right]$

Model Log Logistic (Tsoularis dan Wallace, 2002)

$Y=\beta_{0}\left(1-\beta_{1} \exp \left(-\beta_{2} A\right)^{A /(1 \beta 3)}\right)$

Model Chapman-Richards (Draper dan Smith, 1981)

$\left.Y=\left(\beta_{1} \beta_{2}+\beta_{0} A^{\beta 3}\right)\right) /\left(\beta_{2}+A^{\beta 3}\right)$

Model Morgan - Mercer Flodin (Morgan, P.H, L.P. Mercer dan N.W. Flodin. 1975 dan Seber, G.A.F. dan C.J. Wild. 1989)

Tabel (Table) 1. Jenis dan Sumber Data Serta Metode Pengolahan Data Untuk Analisis (Type and source of data and data analysis method)

\begin{tabular}{|l|l|l|l|}
\hline \multirow{2}{*}{\multicolumn{1}{|c|}{$\begin{array}{c}\text { Analisis } \\
\text { Analysis) }\end{array}$}} & \multicolumn{1}{|c|}{ Denis (Type) } & \multicolumn{1}{|c|}{$\begin{array}{c}\text { Metode } \\
\text { (Method) }\end{array}$} \\
\cline { 2 - 3 } $\begin{array}{l}\text { Model Produksi daun } \\
\text { berdasarkan umur } \\
\text { tunas }\end{array}$ & $\begin{array}{l}\text { Primer : } \\
\text { 1. Berat Biomassa Kayu Putih } \\
\text { 2. Berat DKP sebagai Bahan Baku Industri }\end{array}$ & $\begin{array}{l}\text { Pengukuran } \\
\text { langsung di } \\
\text { lapangan }\end{array}$ & Regresi non-linear \\
\cline { 2 - 3 } & $\begin{array}{l}\text { Sekunder: } \\
\text { 1. Umur Tunas } \\
\text { 2. Risalah Petak Tanaman }\end{array}$ & Perum Perhutani & \\
\hline $\begin{array}{l}\text { Model produksi daun } \\
\text { berdasarkan umur } \\
\text { tanaman (kelompok } \\
\text { umur) }\end{array}$ & $\begin{array}{l}\text { Primer : } \\
\text { 1. Berat biomassa kayu putih } \\
\text { 2. Berat DKP sebagai bahan baku industri }\end{array}$ & $\begin{array}{l}\text { Pengukuran } \\
\text { langsung di } \\
\text { lapangan }\end{array}$ & \multirow{2}{*}{ Regresi linear } \\
\cline { 2 - 3 } & $\begin{array}{l}\text { Sekunder: } \\
\text { 1. Umur tunas } \\
\text { 2. Risalah petak tanaman }\end{array}$ & Perum Perhutani & \\
\hline
\end{tabular}


$Y=\left(\beta_{0}{ }^{(1 \beta 3)}-\beta_{1} \exp \left(-\beta_{2} A\right)^{1 /(1 \beta 3)}\right)$

Model Von-Bartalanffy (Bartalanffy, 1957;

Ratkowskay, 1983; Vanclay, 1994)

$\mathrm{Y}=\beta_{0} /\left(1+\beta_{1} \exp \left(-\beta_{2} \mathrm{~A}\right)\right)^{1 / \beta 3}$

Model Ricard's (Ricard, 1959; Ratkowskay, 1983; Myer, 1986)

$\mathrm{Y}=\beta_{0}-\beta_{1} \exp \left(-\beta_{2}(\mathrm{~A})^{\beta 3}\right)$

Model Weibull (Ratkowskay, 1983; Myer, 1986 dan Seber, 1989)

Keterangan: Y adalah dimensi tegakan, A merupakan umur tegakan; $\exp =\mathrm{e}=2,71828$ dan $\beta_{0}, \beta 1, \beta 2$, $\beta 3$ adalah konstanta

Sehubungan teori model khusus untuk kayu putih belum ada, maka pada penelitian ini digunakan beberapa model persamaan di atas, yang sebagian besar merupakan persamaan regresi nonlinear, dimana lazimnya pertumbuhan benda-benda hidup adalah non-linear. Alasan penggunaan modelmodel persamaan ini adalah model ini tepat digunakan untuk mengukur sebuah fenomena pertumbuhan yang berbentuk sigmoid sepanjang waktu pertumbuhan (fase lengkap pertumbuhan). Model-model ini cocok digunakan karena pada penelitian ini diamati dan diukur tegakan tanaman kayu putih dalam rentang waktu yang lengkap. Untuk model produksi daun dalam satu periode panen diukur umur tunas 1 bulan sampai dengan umur tunas 12 bulan. Sedangkan model produksi daun dalam satu rotasi silvikultur diukur tegakan tanaman kayu putih kelompok umur I (Tanaman umur 5 tahun) sampai dengan kelompok umur VIII (Tanaman umur 38 tahun).

\section{HASIL DAN PEMBAHASAN}

\section{A. Model Produksi Daun pada Satu Daur Pemanenan Tunas}

Data biomassa untuk menyusun model produksi daun kayu putih dalam satu rotasi pangkas dibagi dalam 12 umur tunas dan masing-masing umur tunas diubuat petak ukur sebanyak 3 buah. Ukuran petak ukur adalah $25 \mathrm{~m}$ x $25 \mathrm{~m}$, diperoleh dari hasil kajian penentuan luas optimum petak ukur yang dilakukan sebelum penelitian dilakukan. Penentuan letak plot ukur dan pengumpulan data dilakukan di areal yang mempunyai karakteristik yang sama untuk mengurangi terjadinya keragaman akibat faktor tempat tumbuh, umur tegakan dan varitas tanaman. Rekapitulasi Ratarata Hasil Pengukuran Biomassa pada Petak Ukur Tanaman Kayu Umur Tunas 1 Bulan sampai dengan 12 Bulan, Perhitungan Berat Biomassa Per Pohon dan Per Hektar untuk Penentuan Model Produksi Daun dalam Satu Kali Panen yang dilakukan di tegakan tanaman kayu putih BKPH Sukun disajikan pada Tabel 2.

Tabel(Table) 2. Rekapitulasi hasil pengukuran biomassa tunas kayu putih di BKPH Sukun (Summarized result of biomass measurement of kayu putih sprout at BKPH Sukun)

\begin{tabular}{|c|c|c|c|c|c|c|c|c|c|}
\hline \multirow{2}{*}{$\begin{array}{l}\text { Umur Tunas } \\
\text { (Sprout Age) } \\
\text { (Bulan/Month) }\end{array}$} & \multicolumn{3}{|c|}{$\begin{array}{c}\text { Per Petak Ukur } \\
\text { (Per Sample Plot) } \\
(\mathrm{kg})\end{array}$} & \multicolumn{3}{|c|}{$\begin{array}{l}\text { Per Pohon } \\
\text { (Per Tree }) \\
(\mathrm{kg})\end{array}$} & \multicolumn{3}{|c|}{$\begin{array}{c}\text { Per Hektar } \\
(\text { Per Hectare }) \\
(\mathrm{kg})\end{array}$} \\
\hline & $\begin{array}{c}\text { Biomassa } \\
(\text { Biomass }) \\
\quad(\mathrm{kg})\end{array}$ & $\begin{array}{l}\text { Cabang } \\
(\text { Branch) } \\
\quad(\mathrm{kg})\end{array}$ & $\begin{array}{c}\text { DKP } \\
(\text { Leaf-twig) } \\
(\mathrm{kg})\end{array}$ & $\begin{array}{c}\text { Biomassa } \\
(\text { Biomass }) \\
\quad(\mathrm{kg})\end{array}$ & $\begin{array}{l}\text { Cabang } \\
\text { (Branch) } \\
(\mathrm{kg})\end{array}$ & \begin{tabular}{|c} 
DKP \\
(Leaf- \\
twig) \\
$(\mathrm{kg})$
\end{tabular} & $\begin{array}{c}\text { Biomassa } \\
(\text { Biomass }) \\
\quad(\mathrm{kg})\end{array}$ & $\begin{array}{l}\text { Cabang } \\
(\text { Branch }) \\
(\mathrm{kg})\end{array}$ & $\begin{array}{c}\text { DKP } \\
\text { (Leaf-twig) } \\
(\mathrm{kg})\end{array}$ \\
\hline 1 & 8,31 & 0 & 8,31 & 0,08 & 0 & 0,08 & 132,91 & 0 & 132,91 \\
\hline 2 & 35,09 & 0 & 35,09 & 0,35 & 0 & 0,35 & 561,44 & 0 & 561,44 \\
\hline 3 & 111,58 & 0 & 111,58 & 1,13 & 0 & 1,13 & $1.785,28$ & 0 & $1.785,28$ \\
\hline 4 & 274,72 & 20,89 & 253,83 & 2,78 & 0,21 & 2,57 & $4.395,52$ & 334,24 & $4.061,28$ \\
\hline 5 & 330,63 & 54,65 & 275,98 & 3,32 & 0,55 & 2,77 & $5.290,02$ & 874,35 & $4.415,68$ \\
\hline 6 & 358,80 & 63,02 & 295,78 & 3,62 & 0,64 & 2,99 & $5.740,80$ & $1.008,37$ & $4.732,43$ \\
\hline 7 & 457,05 & 124,52 & 332,45 & 4,63 & 1,26 & 3,37 & $7.312,74$ & $1.992,37$ & $5.319,25$ \\
\hline 8 & 482,55 & 140,81 & 341,74 & 4,86 & 1,42 & 3,44 & $7.720,80$ & $2.253,01$ & $5.467,79$ \\
\hline 9 & 511,08 & 163,01 & 348,07 & 5,16 & 1,65 & 3,52 & $8.177,28$ & $2.608,11$ & $5.569,17$ \\
\hline 10 & 593,82 & 228,74 & 365,08 & 6,04 & 2,33 & 3,71 & $9.501,06$ & $3.659,84$ & $5.841,23$ \\
\hline 11 & 633,26 & 232,64 & 400,61 & 6,37 & 2,34 & 4,03 & $10.132,11$ & $3.722,29$ & $6.409,81$ \\
\hline 12 & 586,85 & 230,09 & 356,76 & 5,93 & 2,32 & 3,60 & $9.389,54$ & $3.681,39$ & $5.708,16$ \\
\hline
\end{tabular}




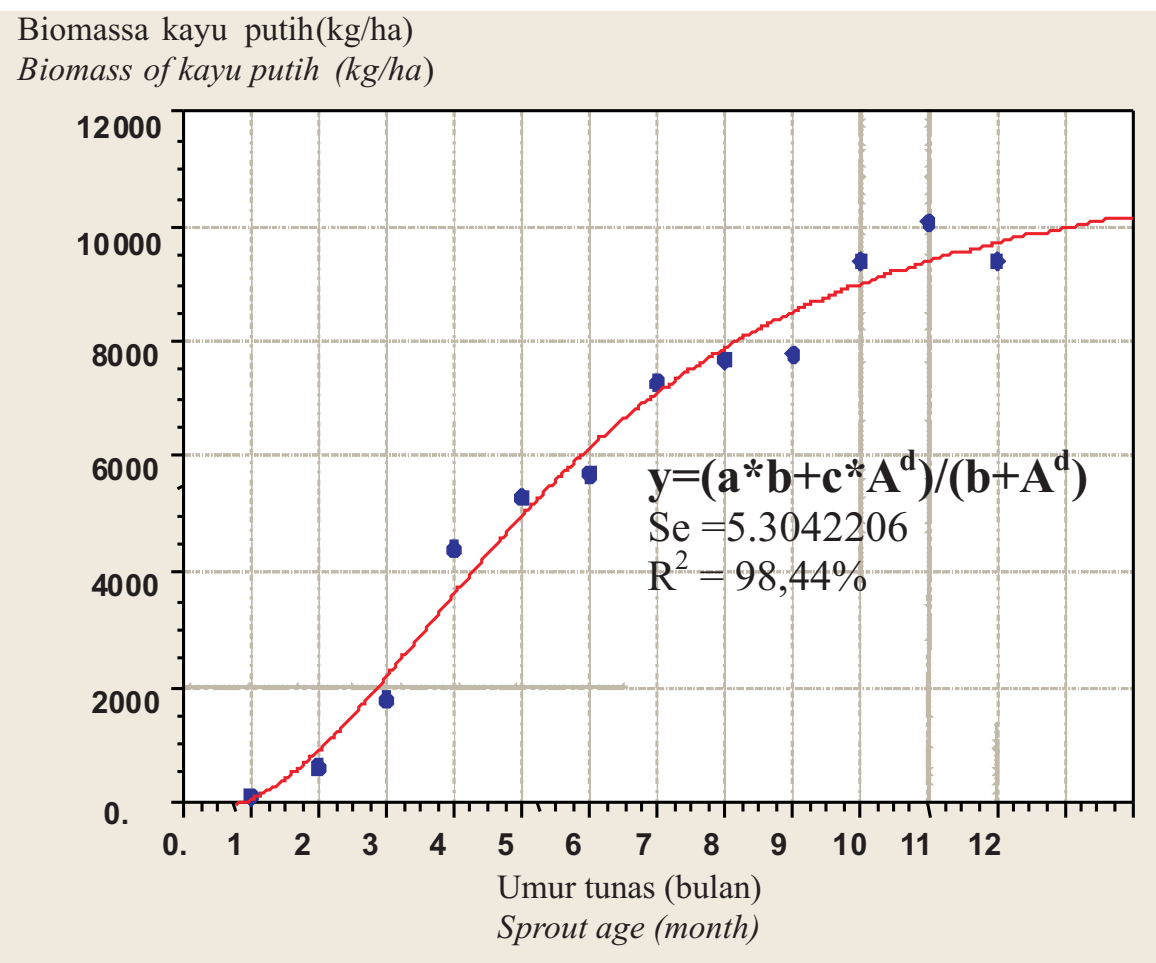

Dimana : $a=-1.9398 ; b=43.1035 ; c=115.5357$ dan $d=2.1950$

Gambar(Figure)2. Kurva hubungan antara produksi biomassa dan umur tunas dengan Model MorganMercer-Flodin (Curve of the correlation between biomass production and sprout age with Morgan-Mercer-Flodin Model)

Dari Tabel 2. di atas dan Gambar 2 dapat diketahui bahwa rata-rata produksi daun segar terus meningkat dari umur tunas 1 bulan sampai dengan umur tunas 11 bulan kemudian menurun pada umur tunas 12 bulan. Pertumbuhan dengan peningkat-an tajam terjadi sampai umur tunas 4 bulan, umur tunas 7 - 11 bulan produksi stabil, yaitu: $7.313-10.132 \mathrm{~kg} /$ ha dan pada umur tunas 12 bulan menurun. Hal ini dapat diartikan bahwa umur tunas 7 bulan dapat dilakukan mulai pemangkasan karena produksi daun mulai stabil.

Hubungan antar umur tegakan dan produksi biomassa maupun DKP dapat dimodelkan dengan beberapa model yang telah digunakan oleh Khamis et al., (2005), dalam tulisannya tentang pemodelan pertumbuhan hasil sawit model pertumbuhan non-linear antara lain yang digunakan adalah model Morgan-Mercer-Flodin. Model ini cocok digunakan untuk menggukur sebuah fenomena pertumbuhan yang menunjukan sebuah bentuk sigmoid sepanjang waktu. Sedangkan model Gompertz, Logistic, Chapman-Richards dan Log-logistic sering digunakan dalam bidang kehutanan (Fekedulegn, et al. (1999). Produksi biomassa baik pada tegakan maupun individu pohon meningkat seiring dengan me-ningkatnya umur tunas. Namun demikian pada umur tunas 12 bulan terjadi penurunan produksi biomassa. Penurunan pada umur 12 bulan merupakan fenomena alami yang terjadi pada pertumbuhan tunas kayu putih, dimana pada umur tersebut terjadi pemangkasan tunas alami (natural pruning) dan perontokan daun tua. Keadaan ini ditunjang pada saat pengambilan data terjadi puncak musim kemarau. Untuk mengetahui berapa besar biomassa yang hilang karena rontok dan saat kapan terjadinya hal tersebut dan apakah setelah tunas berumur 12 bulan atau lebih terjadi penurunan atau justru terjadi kenaikan produksi perlu penelitian lebih lanjut.

\section{B. Riap}

Riap bulan berjaan (current monthly increment: CMI) menunjukkan pertumbuhan tanaman atau tunas setiap bulan, sedangkan riap rata-rata bulanan (mean monthly increment: MMI) menunjukkan pertumbuhan rata-rata dalam waktu tertentu, yang dihitung berdasarkan data terakhir dibagi dengan umur. Akumulasi pertumbuhan, CMI dan MMI digambarkan dalam bentuk grafik 


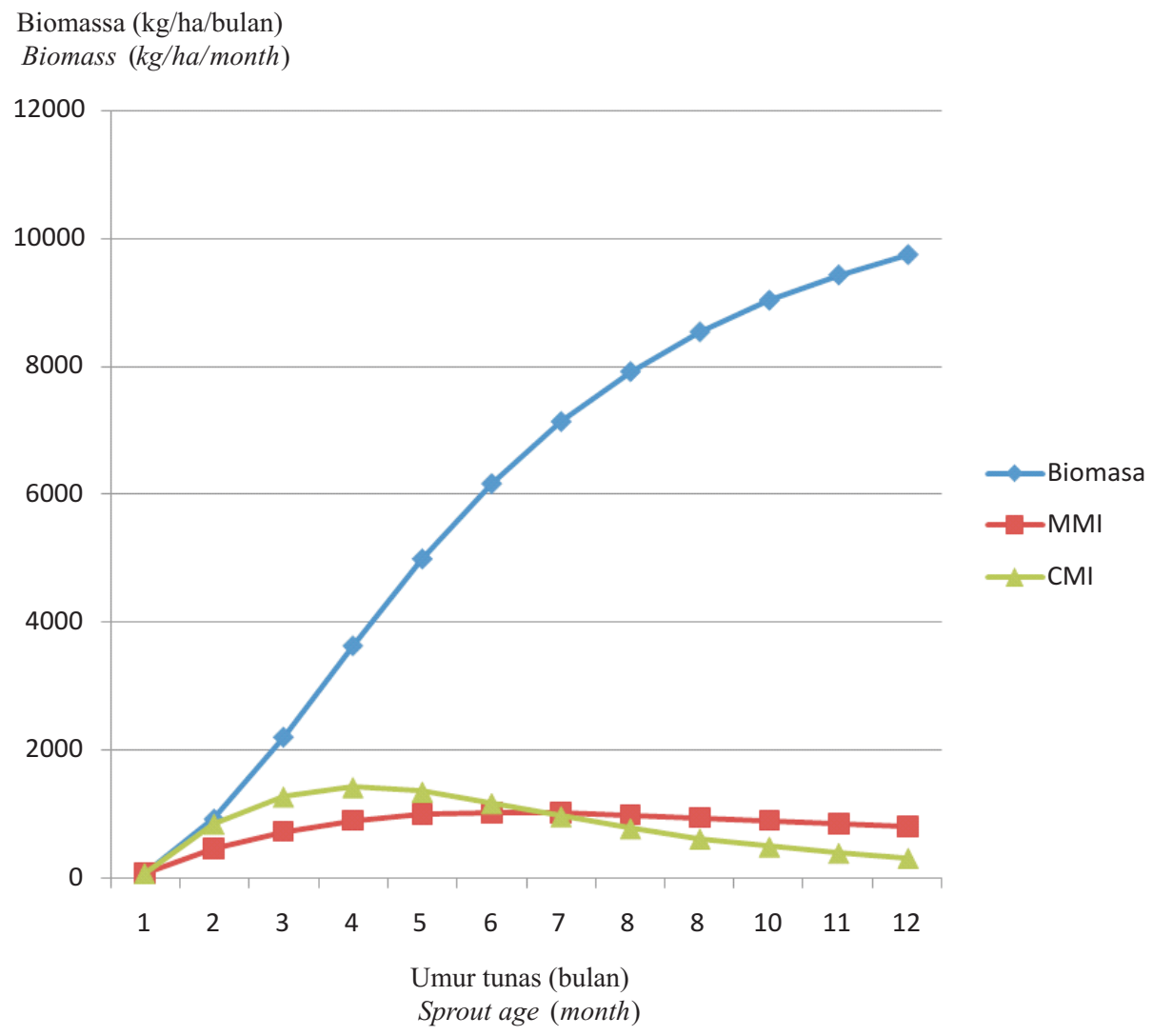

Gambar(Figure) 3. Kurva pertumbuhan biomassa tunas kayu putih, CMI dan MMI(Curve of growth-rate of kayu putih, CMI and MMI)

Tabel (Table) 3. Riap bulan berjalan (CMI) dan riap rata-rata bulanan (MMI) tunas tanaman kayu putih (Curren monthly increment $=C M I)$ and mean monthly increment $=M M I$ of kayu putih sprout)

\begin{tabular}{|c|c|c|c|c|c|c|c|c|c|}
\hline \multirow{3}{*}{$\begin{array}{c}\text { Umur Tunas } \\
\text { (Prout Age) } \\
\text { (Bulan) } \\
\text { (Month) }\end{array}$} & \multirow{2}{*}{\multicolumn{3}{|c|}{ Berat (Weight) }} & \multicolumn{6}{|c|}{ Riap (Increment) } \\
\hline & & & & \multicolumn{3}{|c|}{ CMI } & \multicolumn{3}{|c|}{ MMI } \\
\hline & $\begin{array}{c}\text { Biomassa } \\
\text { (Biomass) } \\
(\mathrm{kg})\end{array}$ & $\begin{array}{c}\text { Cabang } \\
(\text { Branch) } \\
(\mathrm{kg})\end{array}$ & $\begin{array}{c}\text { DKP } \\
(\text { Leaf-Twig) } \\
(\mathrm{kg})\end{array}$ & $\begin{array}{c}\text { Biomassa } \\
\text { (Biomass) } \\
(\mathrm{kg})\end{array}$ & $\begin{array}{c}\text { Cabang } \\
(\text { Branch) } \\
(\mathrm{kg})\end{array}$ & $\begin{array}{c}\text { DKP } \\
\text { (Leaf-Twig) } \\
(\mathrm{kg})\end{array}$ & $\begin{array}{c}\text { Biomassa } \\
\text { (Biomass) } \\
(\mathrm{kg})\end{array}$ & $\begin{array}{c}\text { Cabang } \\
(\text { Branch) } \\
(\mathrm{kg})\end{array}$ & $\begin{array}{c}\text { DKP } \\
\text { (Leaf-Twig) } \\
(\mathrm{kg})\end{array}$ \\
\hline 0 & 0 & 0 & 0 & 0 & 0 & 0 & 0 & 0 & 0 \\
\hline 1 & 132,91 & 0 & 132,91 & 132,91 & 0 & 132,91 & 132,91 & 0,00 & 132,91 \\
\hline 2 & 561,44 & 0 & 561,44 & 428,53 & 0 & 428,53 & 280,72 & 0,00 & 280,72 \\
\hline 3 & $1.785,28$ & 0 & $1.785,28$ & $1.223,84$ & 0 & 1223,84 & 595,09 & 0,00 & 595,09 \\
\hline 4 & $4.395,52$ & 334,24 & $4.061,28$ & $2.610,24$ & 334,24 & 2276,00 & $1.098,88$ & 83,56 & $1.015,32$ \\
\hline 5 & $5.290,02$ & 874,35 & $4.415,68$ & 894,50 & 540,11 & 354,39 & $1.058,00$ & 174,87 & 883,13 \\
\hline 6 & $5.740,80$ & $1.008,37$ & $4.732,43$ & 450,78 & 134,02 & 316,76 & 956,80 & 168,06 & 788,74 \\
\hline 7 & $7.312,74$ & $1.992,37$ & $5.319,25$ & $1.571,94$ & 984,00 & 587,94 & $1.044,68$ & 284,62 & 760,05 \\
\hline 8 & $7.720,80$ & $2.253,01$ & $5.467,79$ & 408,06 & 260,64 & 147,42 & 965,10 & 281,63 & 683,47 \\
\hline 9 & $8.177,28$ & $2.608,11$ & $5.569,17$ & 456,48 & 355,10 & 101,38 & 908,59 & 289,79 & 618,80 \\
\hline 10 & $9.501,06$ & $3.659,84$ & $5.841,23$ & $1.323,78$ & $1.051,73$ & 272,05 & 950,11 & 365,98 & 584,12 \\
\hline 11 & $10.132,11$ & $3.722,29$ & $6.409,81$ & 631,05 & 62,45 & 568,60 & 921,10 & 338,39 & 582,71 \\
\hline 12 & $9.389,54$ & $3.681,39$ & $5.708,16$ & - & - & - & 782,46 & 306,78 & 475,68 \\
\hline
\end{tabular}

untuk menentukan daur tanaman. Daur tanaman sebaiknya ditentukan pada saat kurva MMI bertemu atau berpotongan dengan CMI.

Pada Gambar 3 di atas kurva CMI berpotongan dengan kurva MMI terjadi pada umur tunas 7 bulan, sehingga penentuan titik umur tunas optimum bisa ditentukan berdasarkan perpotongan kurva sampai akhir daur panen. Selain itu, untuk memperoleh hasil maksimal dalam menentukan daur optimum juga diperlukan parameter lain seperti: kadar minyak (rendemen), kualitas minyak (kadar sineol) atau parameter lain 
yang terkait dengan industri minyak kayu putih. Pada gambar tersebut CMI tinggi terjadi pada umur 4 bulan $(2.610,24 \mathrm{~kg} / \mathrm{ha} / \mathrm{bulan})$. MMI sampai umur tunas 4 bulan meningkat selanjutnya riap turun landai dengan bertambahnya umur. MMI pada pertumbuhan tunas kayu putih mulai umur 5 bulan sangat stabil. Namun demikia, dari Tabel 3 diketahui pertumbuhan berat biomassa per hektar kumulatif tunas meningkat dengan bertambahnya umur tunas. Hasil perhitungan riap bulanan berjalan dan riap rata-rata bulanan baik biomassa maupun DKP dapat dilihat pada Tabel 3 .

\section{Model Produksi Daun Pada Satu Daur Silvikultur}

Hasil pengukuran biomassa yang dilakukan di tegakan tanaman kayu putih BKPH Sukun PUS ukuran $25 \mathrm{~m} \times 25 \mathrm{~m}$ sebanyak 3 buah masingmasing tanaman kelompok umur. Hasil pengukuran biomassa pada petak ukur tanaman kayu putih kelompok umur I sampai dengan VIII, perhitungan berat biomassa per hektar untuk penentuan model produksi daun dan kerapatan tegakan direkapitulasi pada Tabel 4. Pada pengukuran ini umur tunas tegakan semua plot ukur adalah seragam yaitu 12 bulan.

Korelasi antara produksi biomassa dan umur tanaman berdasarkan persamaan regresi berhubungan sangat kuat baik pada tegakan maupun individu pohon. Hal ini menunjukan bahwa model produksi biomassa pada hutan tanaman sistem pemanenan pangkas tunas di BKPH Sukun sangat dipengaruhi oleh umur tanaman. Demikian juga korelasi antara produksi DKP dengan umur tanaman mempunyai hubungan yang nyata, walaupun kurvanya lebih landai dibanding dengan kurva produksi biomassa.

Tanaman kayu putih pada umur tanaman 25-an tahun mulai terjadi penurunan produksi. Keadaan ini disebabkan oleh beberapa hal antara lain, pangkas perdana yang kurang baik dan tidak tepat, kebakaran dan pengambilan biomassa yang dilakukan terus menerus. Pemangkasan perdana, yaitu pemotongan pohon setinggi $\pm 110 \mathrm{~cm}$ dari permukaan tanah yang dilakukan saat tanaman berumur 4 tahun setelah tanam. Pemotongan yang tidak tepat mengakibatkan lubang atau celah pada batang kering atau menjadi sarang semut dan rayap. Kebakaran tegakan juga member andil terjadinya penurunan produktivitas biomassa pohon mulai tua karena bentuk batang tidak sempurna lagi.

Terjadinya kebakaran tegakan, pengambilan biomassa yang terus menerus juga menurunkan produktivitas biomassa. Bentuk batang bagian atas tanaman kayu putih yang setiap tahun dipangkas menjadi tidak teratur atau banyak benjolan juga menyebabkan tunas tumbuh tidak maksimal. Selain itu, asupan nutrisi pada tegakan tidak sebanding dengan biomassa yang diambil juga mempengaruhi menurunnya produktivitas biomassa.

Hal ini diperkuat hasil analisis tanah yang dilakukan Sukirno (1994) bahwa tanah hutan

Tabel (Table) 4. Rekapitulasi hasil pengukuran biomassa tegakan kayu putih di BKPH Sukun (Summarized result of biomass measurement of kayu putih stand at BKPH Sukun)

\begin{tabular}{|c|c|c|c|c|c|c|c|c|c|}
\hline \multirow[t]{2}{*}{ No } & \multirow{2}{*}{$\begin{array}{l}\text { Kelompok } \\
\text { Umur } \\
\text { Tegakan } \\
\text { (Stand } \\
\text { Class of } \\
\text { Age) }\end{array}$} & \multirow{2}{*}{$\begin{array}{l}\text { Umur } \\
\text { Tegakan } \\
\text { (Stand } \\
\text { Age })\end{array}$} & \multirow{2}{*}{$\begin{array}{c}\text { Kerapatan } \\
\text { Tegakan } \\
\text { (Stand } \\
\text { Density) } \\
(\%)\end{array}$} & \multicolumn{3}{|c|}{$\begin{array}{c}\text { Berat Per Petak Ukur } \\
\text { Weight Per Sample plot }(\mathrm{kg})\end{array}$} & \multicolumn{3}{|c|}{$\begin{array}{l}\text { Berat Per Hektar } \\
\text { Weight Per Hectare } \\
(\mathrm{kg})\end{array}$} \\
\hline & & & & $\begin{array}{c}\text { Biomassa } \\
\text { (Biomass) } \\
(\mathrm{kg})\end{array}$ & $\begin{array}{c}\text { Cabang } \\
(\text { Branch }) \\
(\mathrm{kg})\end{array}$ & $\begin{array}{c}\text { DKP } \\
\text { (Leaf-Twig) } \\
(\mathrm{kg})\end{array}$ & $\begin{array}{c}\text { Biomassa } \\
\text { (Biomass) } \\
(\mathrm{kg})\end{array}$ & $\begin{array}{c}\text { Cabang } \\
\text { (Branch) } \\
(\mathrm{kg})\end{array}$ & $\begin{array}{c}\text { DKP } \\
\text { (Leaf-Twig) } \\
(\mathrm{kg}) \\
\end{array}$ \\
\hline 1 & I & 5 & 98 & 538,95 & 213,56 & 325,38 & $8.623,15$ & $3.417,01$ & $5.206,13$ \\
\hline 2 & II & 8 & 94 & 691,77 & 286,05 & 405,72 & $11.068,37$ & $4.576,85$ & $6.491,52$ \\
\hline 3 & III & 13 & 69 & 761,54 & 266,45 & 495,09 & $12.184,64$ & $4.263,25$ & $7.921,39$ \\
\hline 4 & IV & 17 & 77 & $1.042,09$ & 350,60 & 691,49 & $16.673,44$ & $5.609,65$ & $11.063,79$ \\
\hline 5 & V & 22 & 45 & 988,30 & 426,88 & 561,42 & $15.812,80$ & $6.830,03$ & $8.982,77$ \\
\hline 6 & VI & 26 & 33 & 795,41 & 418,18 & 377,23 & $12.726,56$ & $6.690,83$ & $6.035,73$ \\
\hline 7 & VII & 34 & 35 & 523,02 & 352,09 & 260,25 & $11.543,52$ & $4.204,21$ & $7.339,31$ \\
\hline 8 & VIII & 38 & 52 & 433,20 & 126,46 & 306,73 & $6.931,15$ & $2.023,41$ & $4.907,73$ \\
\hline
\end{tabular}




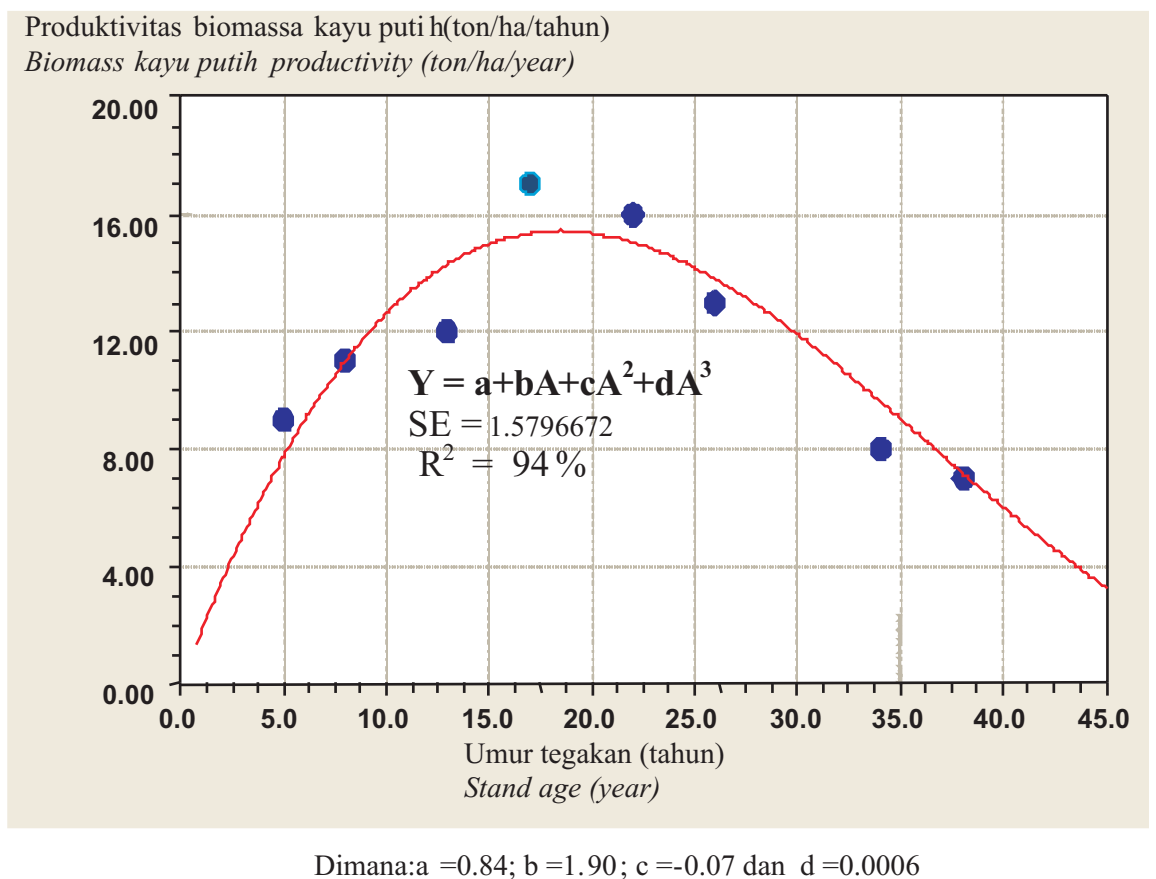

Gambar(Figure) 4. Kurva hubungan produktivitas biomassa dan umur tegakan dengan model Polinomial Fit (Curve of the correlation between biomass production and stand age with Polynomial Fit model).

BKPH Sukun termasuk tanah kurang subur. Adapun hasil analisis tersebut berdasarkan pada kriteria Lembaga Penelitian Tanah Bogor bahwa pH di lokasi penelitian, BKPH Sukun umumnya adalah agak masam sampai netral $(6,10$ - 6,80). Sedangkan unsur hara makro antara lain nitrogen, kalsium, pospor dan bahan organik adalah sebagai berikut: C-tersedia sangat rendah sampai rendah $(0,67 \%-5,02 \%)$, N-total sangat rendah sampai rendah $(0,06 \%$ - 0,10\%), P-tersedia kurang $(0,23 \mathrm{ppm}$ - 2,19 ppm), K-tersedia rendah sampai tinggi $(0,18-0,62)$ sedangkan bahan organik sangat rendah sampai rendah $(1,15 \%-5,47 \%)$. Oleh karena itu, untuk mempertahankan kelestarian kesuburan tanah perlu dilakukan penambahan unsur hara ke dalam tanah yang berupa pupuk atau bahan ornanik lainnya. Sedangkan untuk memulihkan daur hara yang terputus akibat pengangkutan biomassa ke pabrik dan ke rumah penduduk dilakukan melalui pengembalian sisa pabrik yang berupa afval daun kembali ke lahan hutan.

Produktivitas tinggi apabila kerapatan tegakan juga tinggi. Kerapatan tegakan mempunyai korelasi positif dengan produktivitas biomassa apabila dikombinasikan dengan umur tanaman. Hal ini senada dengan hasil kajian Budiadi (2005), bahwa umur tanaman lebih kuat korelasinya dengan produktivitas baik dikombinasikan maupun tidak dikombinasikan dengan kerapatan tegakan. Se- bagai ilustrasi, bahwa tegakan muda dengan kerapatan tinggi di KPH Madiun produksi biomassanya tidak lebih tinggi dibanding dengan tegakan tua, sebaliknya tegakan umur 21 tahun di KPH Indramayu, produksi biomassa lebih besar daripada tegakan umur 31 tahun walaupun kerapatan tegakan lebih kecil.

Secara umum, Gambar 4 menunjukkan bahwa produksi biomassa meningkat seiring dengan bertambahnya umur tegakan. Periode perubahan produktivitas tegakan berdasarkan persamaan regresi yang diperoleh dapat dibagi menjadi tiga, yaitu: Periode naik, periode stabil dan periode turun. Periode naik, tanaman masih muda, batang tanaman relatif kecil dan cabang relatif sedikit, sehingga produksi juga rendah.

Periode stabil, produksi maksimum terjadi pada umur tegakan 13 - 26 tahun atau Kelompok Umur III sampai dengan Kelompok Umur VI, dengan produktivitas $12.185-16.673 \mathrm{~kg} / \mathrm{ha} /$ tahun. Periode produksi maksimum berhubungan erat dengan cara pemanenan atau pemangkasan tunas. Tunas biasanya dipotong $10 \mathrm{~cm}$ di atas batas tumbuh tunas. Jika cara memngkas tunasnya benar, tajuk dapat tumbuh membesar dengan bertambahnya umur tanaman dan biomassa yang dihasilkan juga akan lebih besar (Faculty of Forestry, 1987; Budiadi et al., 2005). 
Periode tegakan turun, tegakan mulai tua dan produksi biomassanya pun mulai menurun. Hal ini terjadi karena menurunnya kemampuan untuk memproduksi biomassa seiring dengan menurunnya kondisi fisiologis pohon dan kerapatan tegakan. Seperti telah disebutkan pada paragraf sebelumnya produktivitas turun kemungkinan disebabkan oleh sering terjadinya kebakaran, kematian pohon, penurunan kualitas tanah akibat pemanenan yang dilakukan terus menerus dan terjadi kompetisi antara tanaman kayu putih dengan tanaman tumpangsari dan gulma. Namun alasan terakhir ini perlu kajian yang lebih mendalam, karena tumpangsari juga bisa member efek positif ketika petani melakukan pemupukan pada tanamannya.

Berdasarkan uraian di atas, untuk mempertahankan kelestarian produksi daun atau biomassa kayu putih, maka tegakan yang telah berumur lebih dari 25 tahun segera diganti dengan tanaman baru.

\section{KESIMPULAN}

\section{A. Kesimpulan}

1. Persamaan matematika untuk kurva pertumbuhan daun tegakan kayu putih yang dipungut dengan sistem pemanenan pangkas tunas dalam satu rotasi panen berbentuk sigmoid, dengan bentuk penduga persamaan sebagai berikut:

$\mathrm{Y}=\left(-1,9398 * 43,1035+115,5357 * \mathrm{~A}^{2,1950}\right)$ $\left(43,1035+\mathrm{A}^{2,1950}\right)\left(\mathrm{R}^{2}=98 \%\right)$.

2. Berdasarkan persamaan matematika untuk kurva produksi daun tersebut pada angka 1 , dapat diketahui bahwa rotasi pemangkasan tunas adalah 7 bulan dihitung dari saat pemangkasan sebelumnya. Akan tetapi apabila umur tajuk tegakan ditentukan dengan kadar minyak tertinggi, maka rotasi pemangkasan daun kayu putih adalah 12 bulan.

3. Persamaan matematika untuk kurva produktivitas daun tegakan kayu putih yang dipanen dengan sistem pemanenan pangkas tunas dalam beberapa rotasi pemangkasan daun merupakan fungsi polinomial dengan bentuk penduga persamaan sebagai berikut: $Y=0,84+1,90 A-0,07 A^{2}+0,0006 A^{3}\left(R^{2}=94 \%\right)$.

4. Berdasarkan model penduga persamaan matematika untuk kurva produksi daun tegakan kayu putih tersebut (kesimpulan 3), maka diperoleh daur biologis untuk tegakan kayu putih adalah 25 tahun.

\section{B. Saran}

Ketelitian dan ketepatan persamaan untuk penduga model pertumbuhan daun kayu putih sangat tergantung kepada ketelitian dan kecukupan data yang dipergunakan untuk menduga model tersebut. Data dengan kualitas yang baik tersebut, memerlukan petak ukur permanen - PUP (permanent sample plot-PSP). Oleh karena itu, maka disarankan pada lokasi penelitian perlu dibuat PUP untuk memperoleh data pertumbuhan tegakan dari waktu ke waktu, sehingga akan dapat diperoleh data produktivitas yang lebih teliti dan lengkap.

\section{DAFTAR PUSTAKA}

Budiadi, Y. H.T. Kanazawa, Ishii, M.S Sabarnurnin, P. Suryanto. 2005. Productivity of Kayu Putih (Melaleuca leucadendron LINN) Tree Plantation Managed in Non-Timber Forest Production System in Java, Indonesia. Agroforestry System (2005) 64: 143-155.

Draper N.R. and H. Smith. 1981. Applied Regression Analisys. Jhon Wiley and Sons, New York.

Faculty of Fotestry. 1987. 'Acacia auriculiformis, Melaleuca leucadendron' Development Section. faculty of Forestry. Gadjah Mada University, Yogyakarta.

Fekedulegn, D. Mairitin, P Mac S. Jim J.C. 1999. Parameter Estimation of Nonlinear Growth Models in Forestry. Silva Fennica 33 (4) 327-336

Gunn, B., M. McDonald, and D. Lea D. 1996. Seed and Leaf Colelections of Melalleuca cajuputil Powell in Indonesia and Nothern Australia. Australian Tree Seed Centre, CSIRO Forest and Forest Product, Canberra, ACT.

Khamis, A., Z. Ismail, K. Haron, and A.T. Muhammed. Nonlinear Growth Models for Modeling Oil Palm Yield Growth. Journal of Mathematics and Statistics 1 (3): 225-233

Morgan, P.H., L.P. Mercer and , N.W. Flodin. 1975. General Model for Nutrional Response of Higher Organisms. Proc.Nat.Acad.Sci.USA. 72:4327-4331.

Mulyadi, T. 2005. Studi Pengelolaan Kayu Putih Melaleuca leucadendron LINN berbasis Ekosistem di BDH Karangmojo, Gunung 
Kidul, Yogyakarta. Thesis. Fakultas Kehutanan. Universitas Gadjah Mada. Yogyakarta. Tidak Diterbitkan.

Myer, R.H. 1986. Clasical and Modern Regression with Applications. Duxubury Press, Boston. 359p.

Nelder, J.A. 1961. The Fitting of a Generalizatiomn of the Logistic Curve. Biometrics 13: 89-110.

Oliver, F.R. 1964. Methode of Estimating the Logistic Function. Applied Satatistics 13: 57-66.

Perum Perhutani. 2011. Rencana Pengaturan Kelestaraian Hutan Kelas Perusahaan Kayu Putih dari KPH Madiun Bagian Hutan: Sukun BKPH Sukun Jangka Perusahaan 1 Januari 2011 s/d 31 Desember 2015. Seksi Perencanaan Hutan II Madiun, Perum Perhutani Unit II Jawa Timur.

Perum Perhutani. 2010. Cayuput Oil. http:// www.perhutaniproducts.com. Akses tanggal 2 Pebruari 2010.

Perum Perhutani. 2005. Rencana Pengaturan Kelestaraian Hutan Kelas Perusahaan Kayu Putih dari KPH Madiun Bagian Hutan: Sukun BKPH Sukun Jangka Perusahaan 1 Januari 2006 s/d 31 Desember 2010. Seksi Perencanaan Hutan II Madiun, Perum Perhutani Unit II Jawa Timur.

Prodan, M. 1968. Forest Biometrics, Translation in Engilsh by S.H. Gardier. Pergamon Press. Oxford.
Ratkowsky, D.A. 1983. Nonlinear Regression Modeling. Marcel Dekker. New York. 276p

Ricards, F.J. 1959. A Flexible Growth Fuction for Empirical Use. Journal of Experimental Botany 10: 290-300.

Rimbawanto, A., N K Kartikawati, L. Baskorowati, M, Susanto ,Prastyono. 2009. Status Terkini Pemuliaan Melaleuca cajuputi. Prosiding Hasil-hasil Penelitian Hal. 148-157. Balai Besar Penelitian Bioteknologi dan Pemuliaan Tanaman Hutan. Yogyakarta.

Seber, G.A.F., C.J. Wild. 1989. Nonlinear Regression . John Wiley and Sons. New York.

Sukirno, D.P. 1994. Kajian Penaksiran Biomas Tanaman Melaleuca leucadendron Linn Umur 6 Tahun di RPH Tambaksari, BKPH Sukun, KPH Madiun. Thesis S-2 Program PPS UGM. Yogyakarta. Tidak Diterbitkan.

Tsoularis, A. dan J. Wallace. 2002. Analysis of Logistic Growth Models. Math. Biosci. 179: 21-55.

Utomo, P.M. 2001. Rekayasa Pengelolaan Hutan Kayu Putih dalam Perspektif Sosial, Ekonomi dan Lingkungan. Thesis. Fakultas Kehutanan. Universitas Gadjah Mada. Yogyakarta. Tidak Diterbitkan.

Vanclay, J.K. 1994. Growth Model for Tropical Forest. CAB International. Wilingford. UK. 380 p.

Von Bertalanffy, L. 1957. Quantitative Laws in Methabolism and Growth. Quart. Rev. Bio. 32:217-231. 
Lampiran (Apendix) 1. Kerangka pemikiran

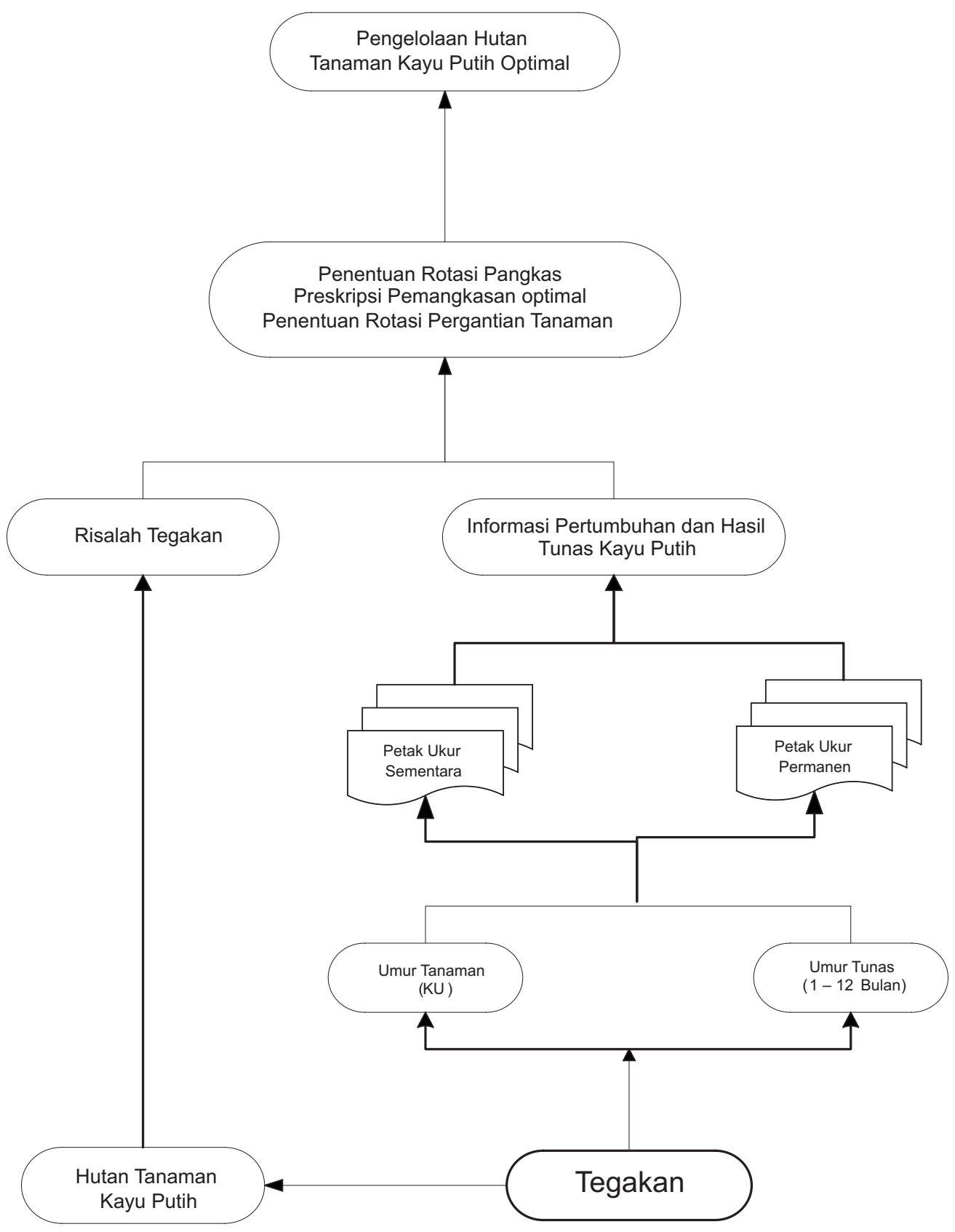

